\title{
Reliability of Geotechnical Parameters in the Analysis of Ancient Landslides
}

\author{
Hamid Pedram \\ Independent Consultant Geotechnical and Engineering Geology, Tehran, Iran \\ Email address: \\ pedram.hamid@yahoo.com
}

\section{To cite this article:}

Hamid Pedram. Reliability of Geotechnical Parameters in the Analysis of Ancient Landslides. Journal of Civil, Construction and Environmental Engineering. Vol. 4, No. 1, 2019, pp. 19-27. doi: 10.11648/j.jccee.20190401.12

Received: November 21, 2018; Accepted: February 26, 2019; Published: March 21, 2019

\begin{abstract}
More than 850 large scale landslides in the two main active seismic zones (Alborz and Zagros) in Iran have been studied over the past nearly four decades. Of these, remedial designs made by the author for major engineering works in the 180 or so landslides encountered in the projects have, to the present, been successful. This work has led me to the conclusion that, regardless of their geotechnical parameters measured on intact samples in the laboratory, the main cause of forming of these landslides has been occurrence of high magnitude recent and historical earthquakes, combined with micro/mega discontinuities existing within the soil/rock masses. In this study, according to the results of geotechnical studies, the stability analysis of ancient landslides in the area of gas transmission lines (IGAT) in Iran, is discussed. Three samples, taken from slip surfaces of ancient landslides of the two main active zones are discussed. The samples were taken from apparently weak soils, but, unexpectedly, they showed good stability strength. The major occurrences of landslides were in the two mentioned active zones (Zagros and Alborz). In the sampling process of the three landslides, samples representative of apparently geotechnically weak rock or poor soil type were the only ones selected for testing and were taken from slip surface/zones with well-defined natural deformation, remolding and slicken siding. Geotechnical and soil shear parameters measured on samples taken from the slip surface showed apparent good results indicating that a landslide should not occur. However this assumption proved to be misleading, for despite these measurements, land sliding did occur. This was especially so in the case of rockslides.
\end{abstract}

Keywords: Ancient Landslide, Slip Surface, Geotechnical Parameters

\section{Introduction}

The stability analysis of natural and engineering slopes is a complex problem, especially when the ancient landslide has to be taken into account. The stability analysis of an ancient landslide is so complicated.

It is distinctive that an ancient landslide, generally characterized by existing slip zones, that can ba instable by excavation with in the slide zone [1]. In recent decades, multiple, many quantitative studies have been carried out to estimate the progressive failure. Potts [2, 3] suggested an approach to simulate the strain-softening properties of brittle soils by reducing the strength. Troncone [4] offered the results of a numerical study on a landslide in deep excavations at the slope toe and further extended this analysis into a three dimensional problem [5]. Many countries are facing increasing pressure to ensure the safe transport of energy, especially by pipelines, as global economic development results in greater energy demand. So great attention is placed on the safety assessment $[6,7]$, and design of pipelines [8]. landslides are gaining much attention because of their potentially devastating effects on the integrity of gas pipelines. Deng et al. [9] simplified pipelines inside and outside a slope to determine internal stresses and deformations.

In this study, according to the results of geotechnical studies, the stability analysis of ancient landslides in the area of gas transmission lines (IGAT) in Iran, is discussed.

\section{Tectonic and Seismology of the Iranian Plateau}

The occurrence of large scale landslide as the result of earthquake and tectonic activity is a common phenomenon in Iran and has been occurring over many centuries. 
The Iranian plateau is situated on the Himalayan earthquake belt, where destructive earthquakes are frequent and repeated events. In addition, countless low-magnitude earthquakes are common and being recorded daily. Although no part of the plateau is safe from earthquakes, the two major active fold belts, namely Zagros and Alborz, are the most affected zones (Figure 1). In a broader study than presented here some other zones with varying seismicity and geological conditions can be recognized in Iran. Where an ancient landslide is present, but which has not been recognized as such, problems will arise when excavations and building operations have been carried out or are in progress. This is because one or more slip surfaces have been formed, so any excavation can upset the balance and equilibrium state.

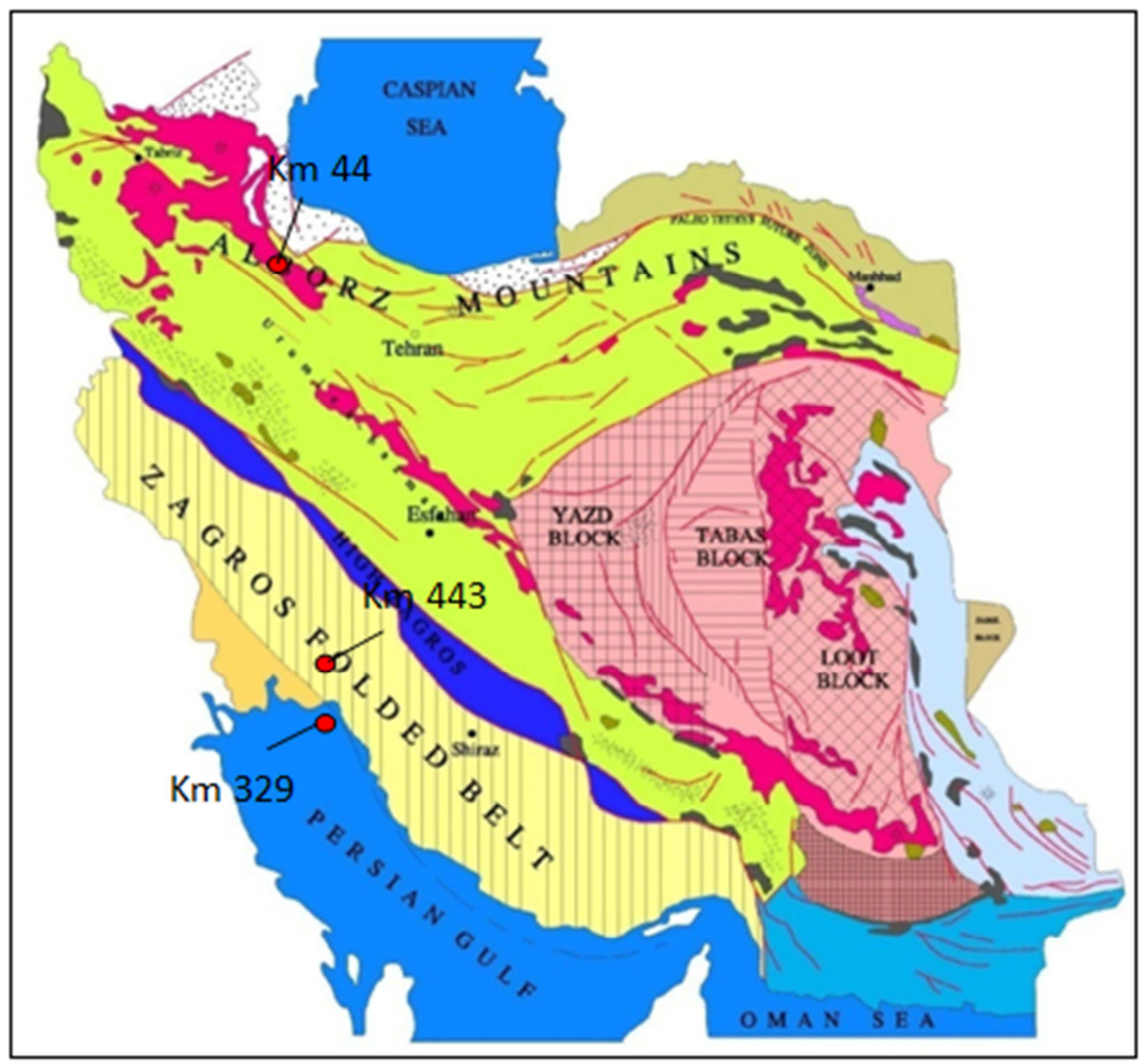

Figure 1. Structural Map of Iran showing the two major active folded belts, namely Zagros and Alborz [10].

The development of a suitable design to mitigate or eliminate the hazard of slope failure in an unrecognized ancient landslide, and thus secure the planned structure, requires time and investment.

On the other hand, it should be noted that minor slope failures due to excavations and collapse of excavation walls can be managed and should not be mistaken for major complications.

Ancient landslides can have occurred in any rock or soil type. In this paper three samples, taken from slip surfaces of ancient landslides of the two main active zones are discussed. Sampling of slip surfaces is a difficult and dangerous process, but it is necessary to obtain a good and undisturbed sample. Any sort of machinery drilling which is frequently used to obtain samples for laboratory testing can produce misleading results, because it is almost impossible to identify and locate the slip surface/zone correctly in such a small recovered sample, especially when the slip surface has been formed as a zone and not a simple surface. Thus the term "slip surface" may rightly be either a plane or a thin zone. No zones more than $80 \mathrm{~cm}$ thick have yet been observed. The author reiterates this point: the term slip SURFACE can be misleading because it might be a thin zone.

The samples which are discussed below were taken from apparently weak soils, but, unexpectedly, they showed good stability strength. Other slip surface samples, with much better geotechnical characters, are not discussed here.

After the 1990 Manjil earthquake (Ms=7.4) Pedram [11] indicated that although more than 110 landslides were induced in many rock/soil types none of the ancient landslides present in the affected area was reactivated. This is still my firm opinion and only interference by man or river undercutting reactivates them. This is a fact to be considered in any analyses or designs.

The first distribution map of landslides, based on 250 examples in Iran, was published by the author [12] after the Manjil 1990 earthquake. Later, in a broader collection of data (2050 cases), despite the difference in the numbers noted in the two lists, the outcome was similar [13]. The major occurrences of landslides were in the two mentioned active zones (Zagros and Alborz). In Figure 2 position studded area has shown in the map of Iran. 


\section{Location and Sampling}

In the sampling process of the three landslides discussed below samples representative of apparently geotechnically weak rock or poor soil type were the only ones selected for testing and were taken from slip surface/zones with welldefined natural deformation, remolding and slicken siding.

\subsection{Km.329, IGAT II landslide}

Km.329, IGAT II (Iranian Gas Trunkline) landslide (Figure
3) is located in the Zagros region (Figure 2). It has a downslope length of nearly $400 \mathrm{~m}$. And width of $250 \mathrm{~m}$. A hand-bored pit about $1 \mathrm{~m}$. in diameter was excavated (Figure3, point A) so that the slip surface/zone could be examined and identified visually. The sample taken was a block $60 \times 70 \times 30 \mathrm{~cm}$. The depth of sampling was $12 \mathrm{~m}$ from the excavated service road and $19 \mathrm{~m}$ deep from the natural ground level. In this case the slip appeared as a zone almost $50 \mathrm{~cm}$ thick. landslide occurred in fine grain soils.

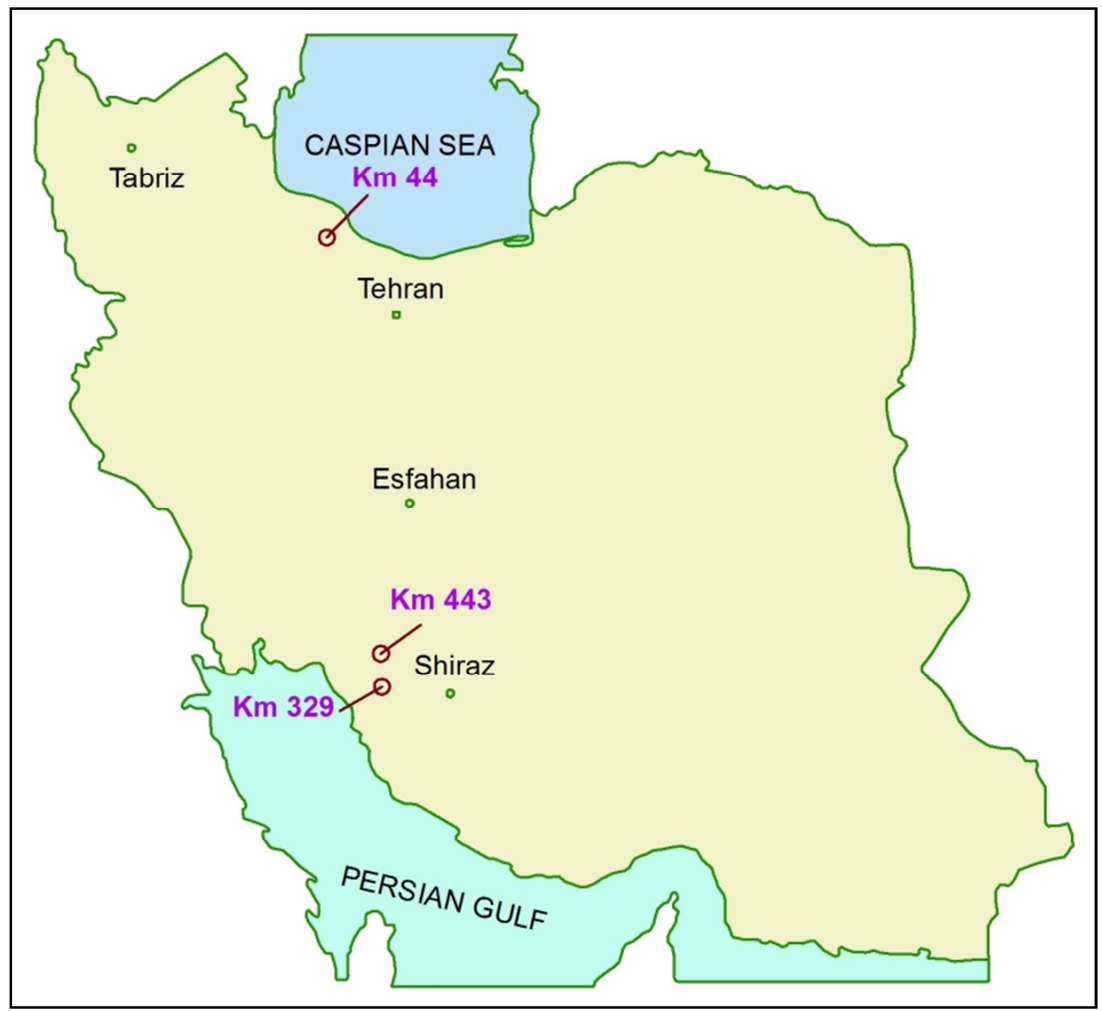

Figure 2. Study Area on Map of Iran.

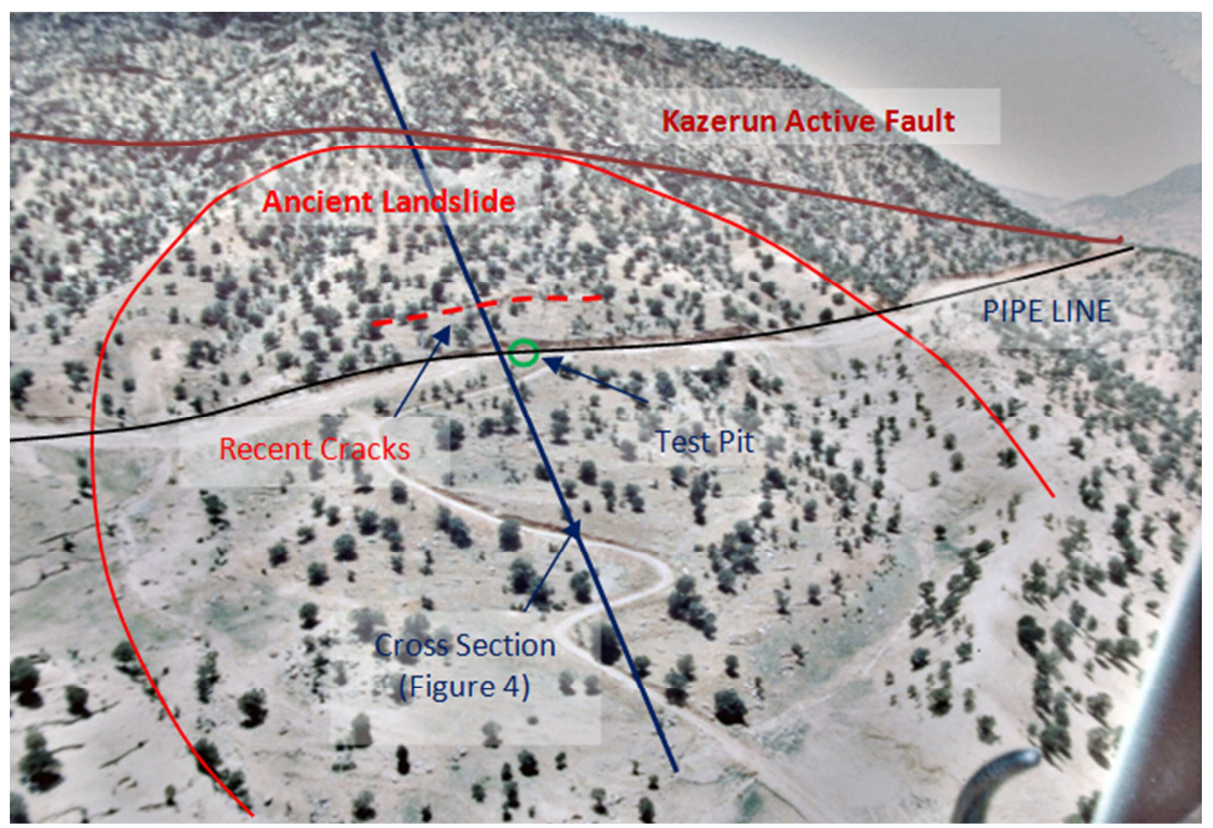

Figure 3. Km. 329 IGAT II landslide (Zagros). 
The undisturbed samples were recovered from the samped blocks and were tested in the laboratory. The test results are shown in table 1. A geological cross section of Km. 329 IGAT II landslide shown in figure 4.

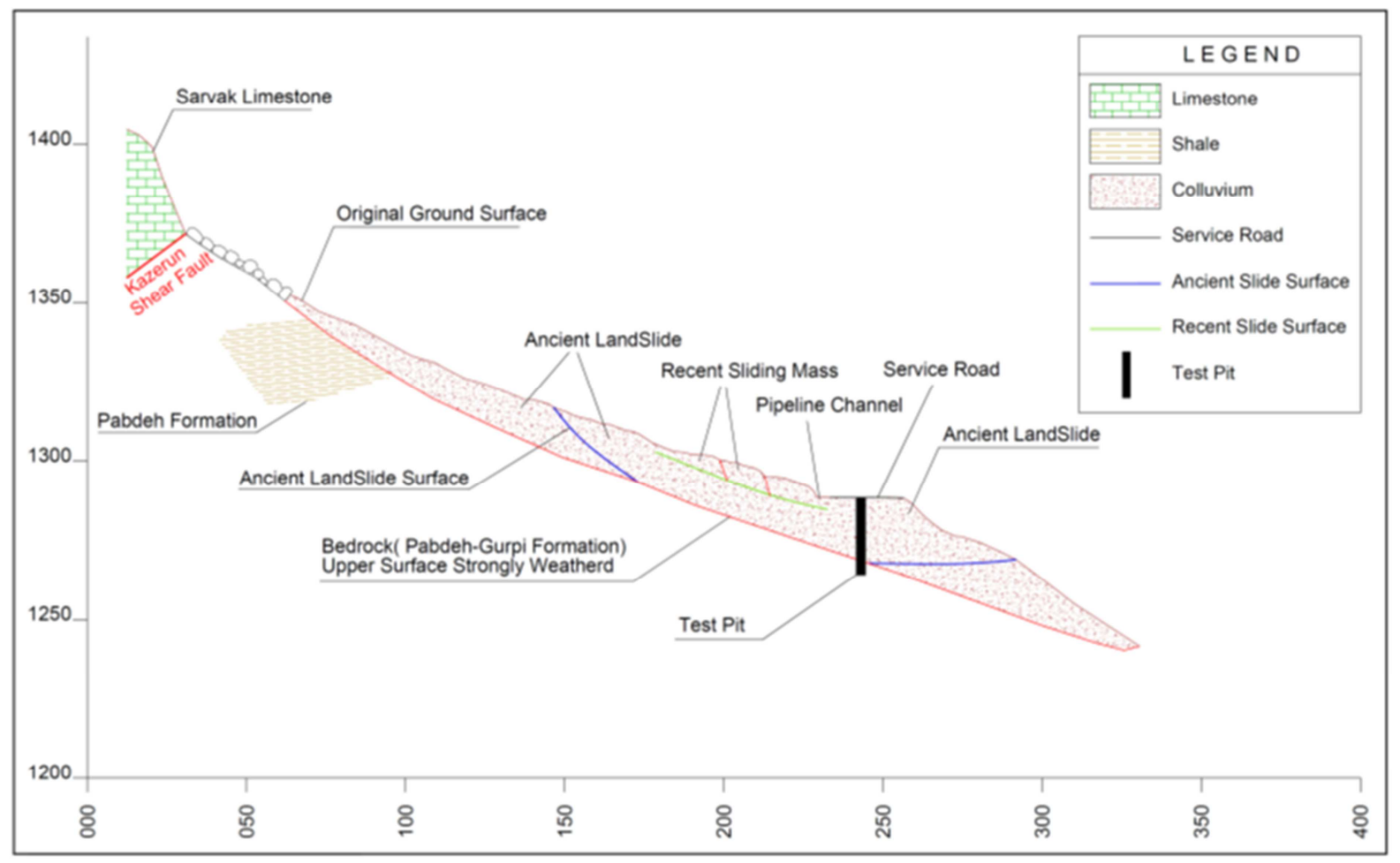

Figure 4. Geological cross section, Km. 329 IGAT II (Zagros).

Based on the geotechnical parameters obtained from laboratory testing (Table 1), back analyses were performed using the Geo Studio $/ 2007$ program. To obtain the safety factor the Morgenstern-Price procedure was used. In this procedure forces equilibrium and moment equilibrium controlled together. It is worthwhile mentioning here that using any other widely -used programs will lead more or less to the same results; only small differences will be observed. In no analysis has the slip surface been considered as a hazardous element; so the calculated safety factor from any analysis is going to be under question.

Table 1. Km.329 sample Test results.

\begin{tabular}{|c|c|c|c|c|c|c|c|c|c|c|c|}
\hline \multirow{2}{*}{\multicolumn{2}{|c|}{$\begin{array}{l}\text { Identification } \\
\text { Sample }\end{array}$}} & \multirow{3}{*}{$\begin{array}{l}\text { Depth From } \\
\text { (m) }\end{array}$} & \multirow{3}{*}{ Description } & \multicolumn{8}{|c|}{ Classification } \\
\hline & & & & \multicolumn{4}{|c|}{ Particle Size distribution Passing \% } & \multicolumn{3}{|c|}{ Atterberg Lmit } & \multirow{2}{*}{$\begin{array}{l}\text { Moisture \% } \\
\text { W }\end{array}$} \\
\hline No. & Type & & & $76 \mathrm{~mm}$ & $4.8 \mathrm{~mm}$ & $76 \mu$ & $2 \mu$ & LL & PL & PI & \\
\hline 1 & $\begin{array}{l}\text { Km 329+000 } \\
\text { Pipeline }\end{array}$ & $\begin{array}{l}10 \text { (Slip } \\
\text { Surface) }\end{array}$ & $\begin{array}{l}\text { L.Br. Very Stiff } \\
\text { Lean CLAY }(\mathrm{CL})\end{array}$ & & 100 & 86 & 24 & 34 & 22 & 12 & 16.9 \\
\hline
\end{tabular}

Table 1. Continue.

\begin{tabular}{|c|c|c|c|c|c|c|c|c|c|c|c|}
\hline \multirow{2}{*}{$\begin{array}{l}\text { Dencity } \\
\text { Bulk } \\
\text { Dencity } \\
\left(\mathrm{g} / \mathrm{cm}^{3}\right)\end{array}$} & \multirow[b]{2}{*}{$\begin{array}{l}\text { Dry } \\
\text { Dencity } \\
\left(\mathrm{g} / \mathrm{cm}^{3}\right)\end{array}$} & \multirow[b]{2}{*}{$\begin{array}{l}\text { Specific } \\
\text { Gravity }\end{array}$} & \multicolumn{6}{|c|}{ Strength } & \multicolumn{3}{|c|}{ Consolidation } \\
\hline & & & \multicolumn{2}{|c|}{$\begin{array}{l}\text { S.P.T Blow Per } \\
30 \mathrm{~cm}\end{array}$} & \multicolumn{2}{|c|}{ Triaxial Tests } & \multicolumn{2}{|c|}{ Effective Stress Tests } & \multirow{2}{*}{$\begin{array}{l}\begin{array}{l}\text { Pressure } \\
\text { Range } \\
(\mathrm{kg} / \mathrm{cm} 2)\end{array} \\
\sigma_{1}\end{array}$} & \multirow{2}{*}{$\begin{array}{l}\mathrm{cm}^{2} / \mathbf{k g} \times 10^{2} \\
\mathrm{~m}_{\mathrm{v}}\end{array}$} & \multirow{2}{*}{$\begin{array}{l}\mathrm{cm}^{2} / \mathrm{sec} \times 10^{-3} \\
c_{\mathrm{v}} \\
\end{array}$} \\
\hline$\gamma_{\text {wet }}$ & $\gamma_{\mathrm{d}}$ & $\gamma_{\mathrm{s}}$ & $\mathbf{N}$ & $\mathbf{N}_{70}$ & $\varphi$ (Degree) & C (Kpa) & $\varphi^{\prime}($ Degree $)$ & $\mathrm{C}^{\prime}$ (Kрa) & & & \\
\hline \multirow{4}{*}{2.11} & \multirow{4}{*}{1.8} & \multirow{4}{*}{2.684} & \multirow{4}{*}{ - } & \multirow{4}{*}{ - } & \multirow{4}{*}{3} & \multirow{4}{*}{0.98} & \multirow{4}{*}{31} & \multirow{4}{*}{0.06} & $0.5-1$ & 0.09 & 7.56 \\
\hline & & & & & & & & & $1-2$ & 1.16 & 5.47 \\
\hline & & & & & & & & & $2-4$ & 0.87 & 3.41 \\
\hline & & & & & & & & & $4-8$ & 0.56 & 4.26 \\
\hline
\end{tabular}

The results of the analysis for the landslide at $\mathrm{Km} .329$ IGAT II (Table 1) for both total stress (UU) and effective stress $(\mathrm{CD})$ are presented below:

A-Considering total stress (UU) parameters of the soil mass (Table 1)

$$
\mathrm{C}=98 \mathrm{kPa}
$$

$$
\varnothing=3^{\circ}
$$

In this condition $\mathrm{FS}=1.669$ (figure 5) thus confirming the soil stability 
By introducing an earthquake with horizontal ground acceleration of $0.22 \mathrm{~g}$ (Based on seismological studies), the safety factor drops to less than 1 . At this stage the soil mass is on the verge of failure. In pseudo- static analysis this coefficient of earthquake, corresponds to an earthquake with horizontal ground acceleration of $0.45-0.65 \mathrm{~g}$.

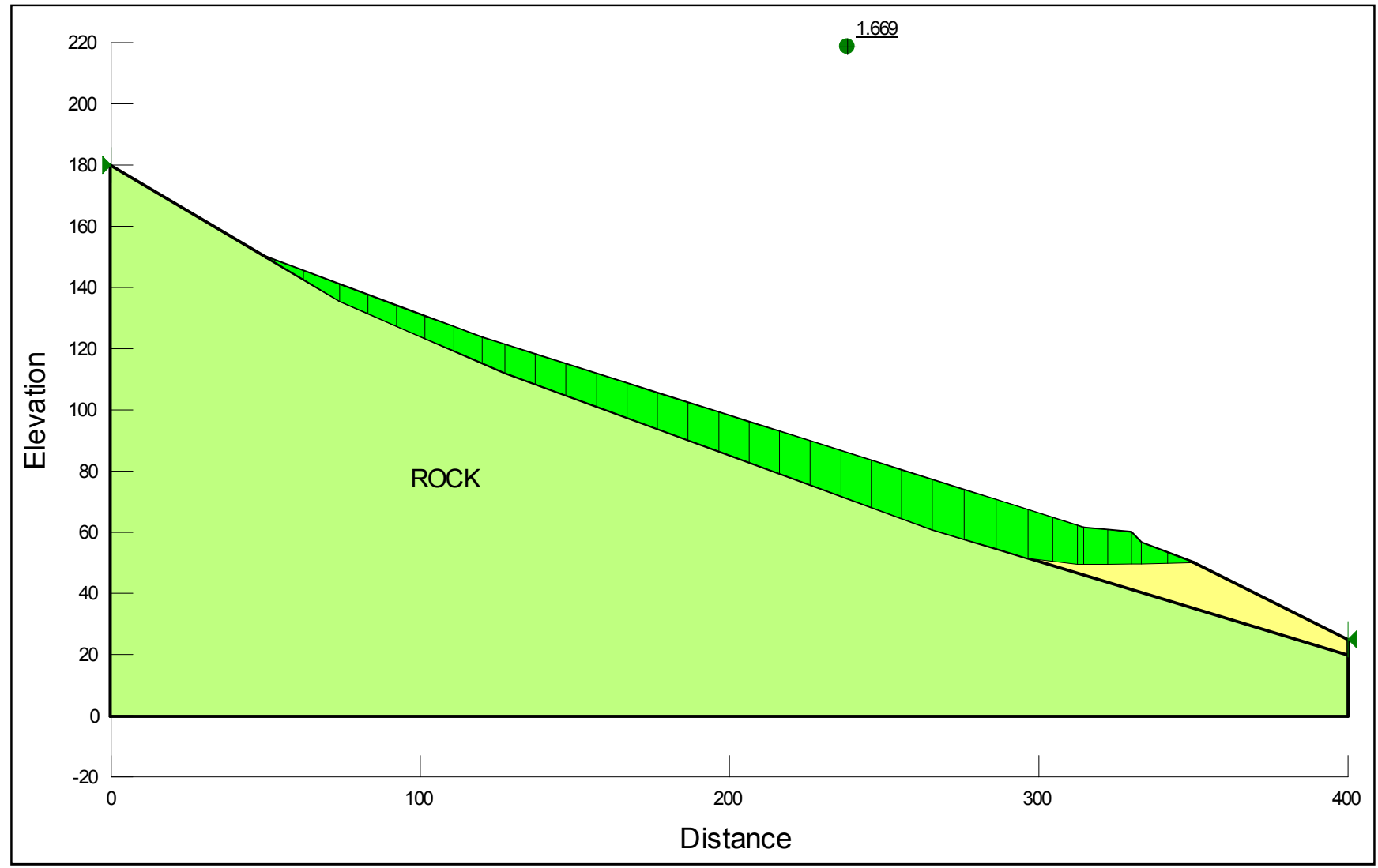

Figure 5. Factor of safety in slope stability analysis, Km. 329 IGAT II.

In a trial and error procedure, to bring the soil mass into the failure threshold, the values of the geotechnical parameters have to be reduced so that the safety factor drops to less than 1 . Which is:

$$
\begin{gathered}
\mathrm{C}_{\text {slide }}=58.7 \mathrm{KPa} \\
\emptyset_{\text {slide }}=1.8^{\circ}
\end{gathered}
$$

In this state soil failure begins.

B-Considering effective stress (CD) parameters of the soil mass ( Table 1)

$$
\begin{gathered}
\mathrm{C}=6 \mathrm{KPa} \\
\varnothing=31^{\circ}
\end{gathered}
$$

In this condition Fs $=2.019$ which confirms the soil stability

By introducing an earthquake with horizontal ground acceleration of $0.275 \mathrm{~g}$, the safety factor drops to less than 1 . At this stage the soil mass is on the verge of failure. This coefficient of an earthquake in pseudo- static analysis corresponds to an earthquake with horizontal ground acceleration of $0.55-0.825 \mathrm{~g}$.

In a trial and error procedure, to bring the soil mass into the failure threshold, the values of the geotechnical parameters have to be reduced so that the safety factor drops to less than 1. Which is:

$$
\begin{aligned}
& \mathrm{C}_{\text {slide }}=3 \mathrm{KPa} \\
& \emptyset_{\text {slide }}=16.57^{\circ}
\end{aligned}
$$

At this state soil failure begins.

\subsection{Km. 44 IGAT IV landslide}

Km. 44 IGAT IV landslide (Figure 6) is located in Alborz (Figure 1). It has an average of $2 \mathrm{~km}$ length, nearly $1 \mathrm{~km}$ width, and depth of sampling $23 \mathrm{~m}$ from the natural ground level. A sample $70 \times 70 \times 30 \mathrm{~cm}$ was taken from an excavation hole by using a hydraulic excavator. Here the slip appeared as a zone $80 \mathrm{~cm}$ thick. The slip zone is well defined by remolding, deformation and conspicuous slicken siding. 


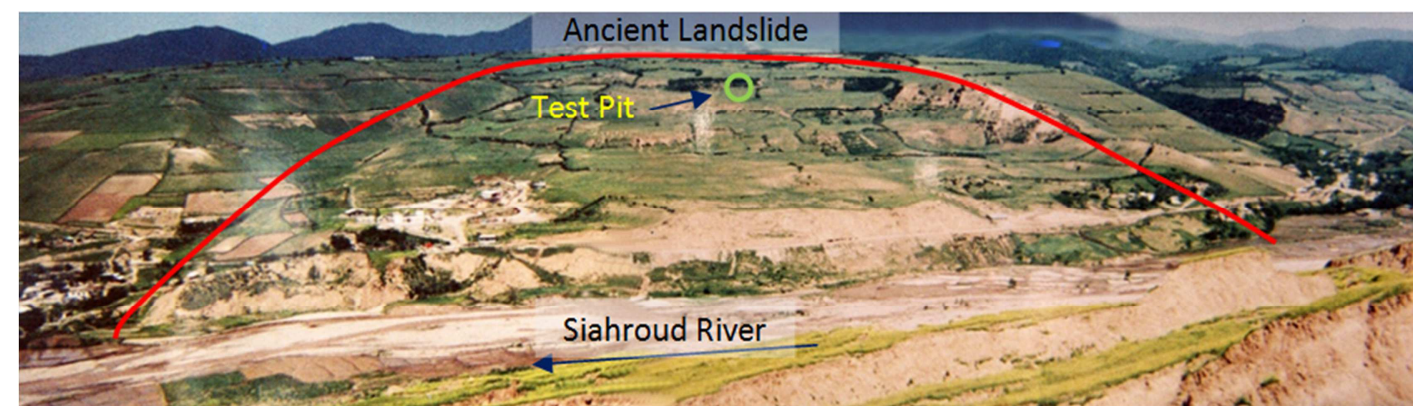

Figure 6. Schematic of Km. 44 IGAT IV landslide (W. Alborz).

The undisturbed samples were recovered from the sampled blocks and were tested in the laboratory. Samples Composed of fine grain soils named loess. The test results are shown in table 2.

Based on the same procedure as mentioned above, back analyses were performed. The results of the analysis for the landslide at Km.44 IGAT IV (Table 2) for both total stress (UU) and effective stress (CD) are presented below:
A-Considering total stress (UU) parameters of the soil mass (Table 2)

$$
\mathrm{C}=75 \mathrm{KPa}
$$

$\varnothing=2^{\circ}$

Table 2. Km.44 sample Test results.

\begin{tabular}{|c|c|c|c|c|c|c|c|c|c|c|c|}
\hline \multirow{2}{*}{\multicolumn{2}{|c|}{$\begin{array}{l}\text { Identification } \\
\text { Sample } \\
\end{array}$}} & \multirow{3}{*}{ Depth From (m) } & \multirow{3}{*}{ Description } & \multicolumn{8}{|c|}{ Classification } \\
\hline & & & & \multicolumn{4}{|c|}{ Particle Size distribution Passing \% } & \multicolumn{3}{|c|}{ Atterberg Lmit } & \multirow{2}{*}{$\begin{array}{l}\text { Moisture \% } \\
\text { W }\end{array}$} \\
\hline No. & Type & & & $76 \mathrm{~mm}$ & $4.8 \mathrm{~mm}$ & $76 \mu$ & $2 \mu$ & $\mathbf{L L}$ & PL & PI & \\
\hline 1 & Km 44+000 Pipeline & 20 (Slip Surface) & L.Br.Stiff Lean CLAY (CL) & & 100 & 87 & 28 & 46 & 26 & 21 & 20.3 \\
\hline
\end{tabular}

Table 2. Continue.

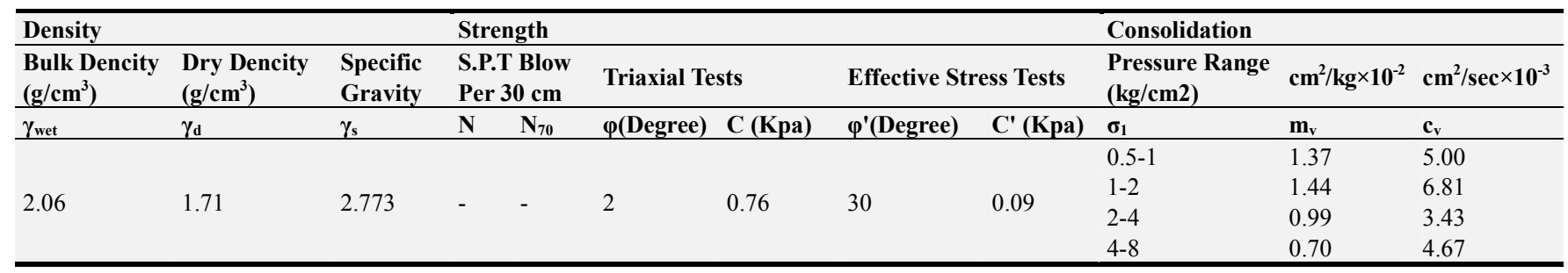

In this condition FS $=1.996$ (figure 7) thus confirming the soil stability

By introducing an earthquake with horizontal ground acceleration of $0.118 \mathrm{~g}$ (based on seismological studies), the safety factor drops to less than 1 . At this stage the soil mass is on the verge of failure. In pseudo- static analysis this coefficient of earthquake, corresponds to an earthquake with horizontal ground acceleration of $0.24-0.36 \mathrm{~g}$.

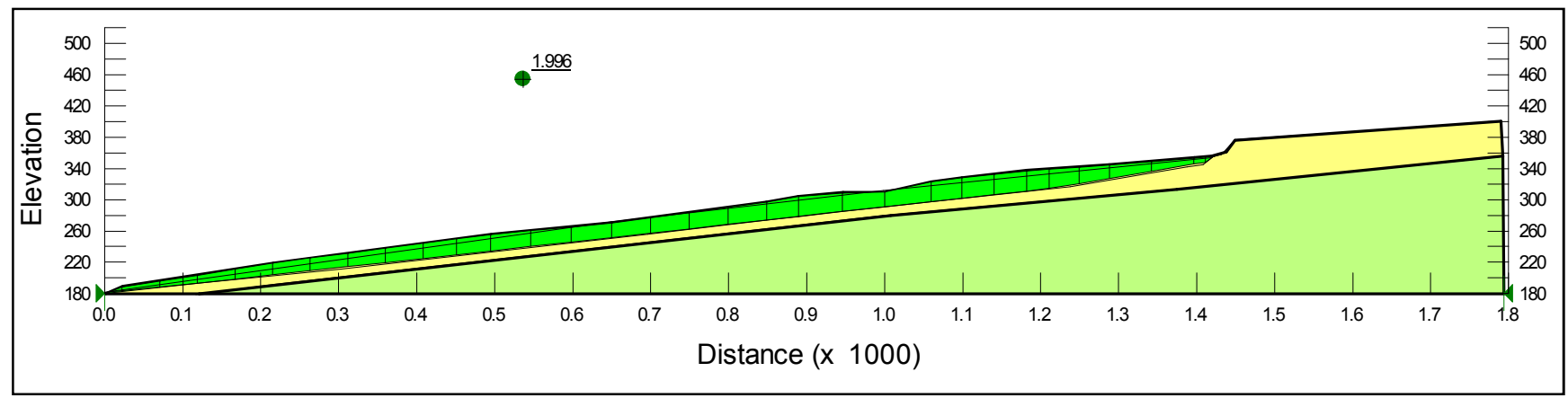

Figure 7. Factor of safety in slope stability analysis, Km. 44 IGAT IV.

In a trial and error procedure, to bring the soil mass to the failure threshold, the values of the geotechnical parameters have to be reduced so that the safety factor drops to less than 1.Which is:

$$
\mathrm{C}_{\text {slide }}=37.5 \mathrm{KPa}
$$$$
\emptyset_{\text {slide }}=1^{\mathrm{o}}
$$ 
In this state soil failure begins.

A-Considering effective stress (CD) parameters of the soil mass (Table 2 )

$$
\begin{gathered}
\mathrm{C}=9 \mathrm{KPa} \\
\varnothing=30^{\circ}
\end{gathered}
$$

In this condition $\mathrm{Fs}=4.775$ which confirms the soil stability

By introducing an earthquake with horizontal ground acceleration of $0.44 \mathrm{~g}$ (based on seismological studies), the safety factor drops to less than 1.At this stage the soil mass is on the verge of failure. This coefficient of earthquake in pseudo- static analysis corresponds to an earthquake with horizontal ground acceleration of $0.9-1.2 \mathrm{~g}$.

In a trial and error procedure, to bring the soil mass into the failure threshold, the values of the geotechnical parameters have to be reduced so that the safety factor drops to less than 1.Which is:

$$
\begin{gathered}
\mathrm{C}_{\text {slide }}=1.8 \mathrm{KPa} \\
\emptyset_{\text {slide }}=6.5^{\circ}
\end{gathered}
$$

At this state soil failure begins.

\subsection{Km.443, IGAT II landslide}

Km.443, IGAT II landslide (Figure8) is situated in Zagros almost $300 \mathrm{~m}$. In length, about $100 \mathrm{~m}$. width and $12 \mathrm{~m}$. deep from the original natural ground level. The sample was taken after excavation for construction of the service road, i.e. 5.5 m. deep using a hydraulic excavator. The slip surface was sharply defined as a plane and developed in a weak and weathered rock of marl.

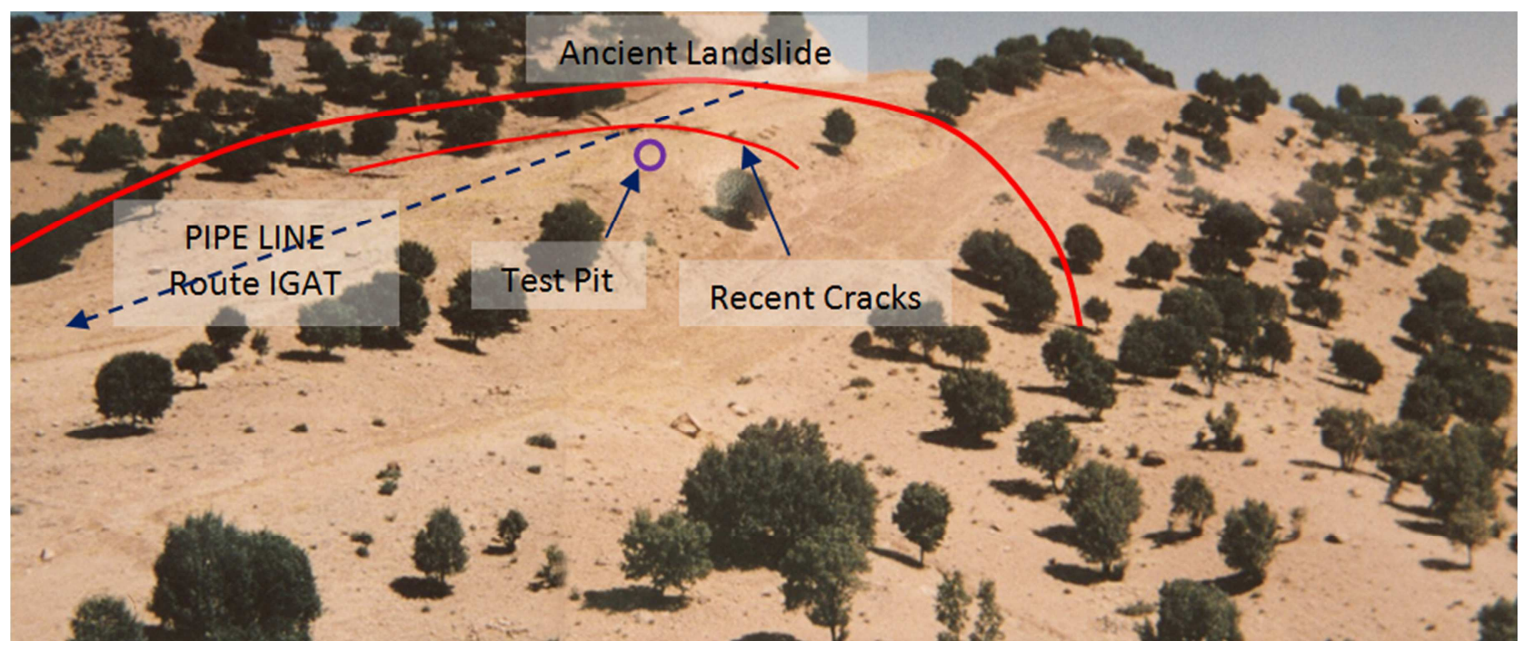

Figure 8. Km.443 IGAT II landslide (Zagros).

\begin{tabular}{|c|c|c|c|c|c|c|c|}
\hline \multicolumn{8}{|c|}{ Laboratory Soil Test (IIEES*) } \\
\hline \multicolumn{8}{|c|}{ Direct Shear Test } \\
\hline \multicolumn{8}{|c|}{ Project: Km P. 443 IGAT II } \\
\hline \multicolumn{8}{|c|}{ Diameter: $6 \mathrm{~cm}$ Width: $2 \mathrm{~cm}$ Area: $28.26 \mathrm{~cm} 2$ Depth: $5 \mathrm{~m}$ (from Slip Surface) } \\
\hline \multicolumn{8}{|c|}{ Coefficient of ring: 0.4 Velocity: $0.05 \mathrm{~mm} / \mathrm{min}$} \\
\hline No. test & W\% Before test & $\begin{array}{l}\text { Dry Dencity } \\
\text { gr/cm }\end{array}$ & W\% After Test & $\begin{array}{l}\text { Normal Load } \\
\text { Kgf/cm2 }\end{array}$ & $\begin{array}{l}\text { Shear Load } \\
\text { Kgf/cm2 }\end{array}$ & $\mathrm{C} \mathrm{Kgf} / \mathrm{cm}^{2}$ & Phi Degree \\
\hline 1 & 17 & 1.82 & 18 & 1 & 2.3354565 & & \\
\hline 2 & 17 & 1.82 & 17 & 2 & 2.6185421 & 2 & 18 \\
\hline 3 & 17 & 1.82 & 16.2 & 3 & 2.9723992 & & \\
\hline *: Interna & tute of Earthquake & tgineering and & ology & & & & \\
\hline
\end{tabular}

The undisturbed samples were recovered from the obtained blocks and were tested in the laboratory. The test results are shown in table 3.

Table 3. Km.443 sample Test results.

Slope stability analysis of the cross section for Km.443 IGAT II landslide was performed by the same software considering geotechnical parameters in table 3 (see Figure 9). The factor of safety value is so great that it leaves no expectation of any instability. 


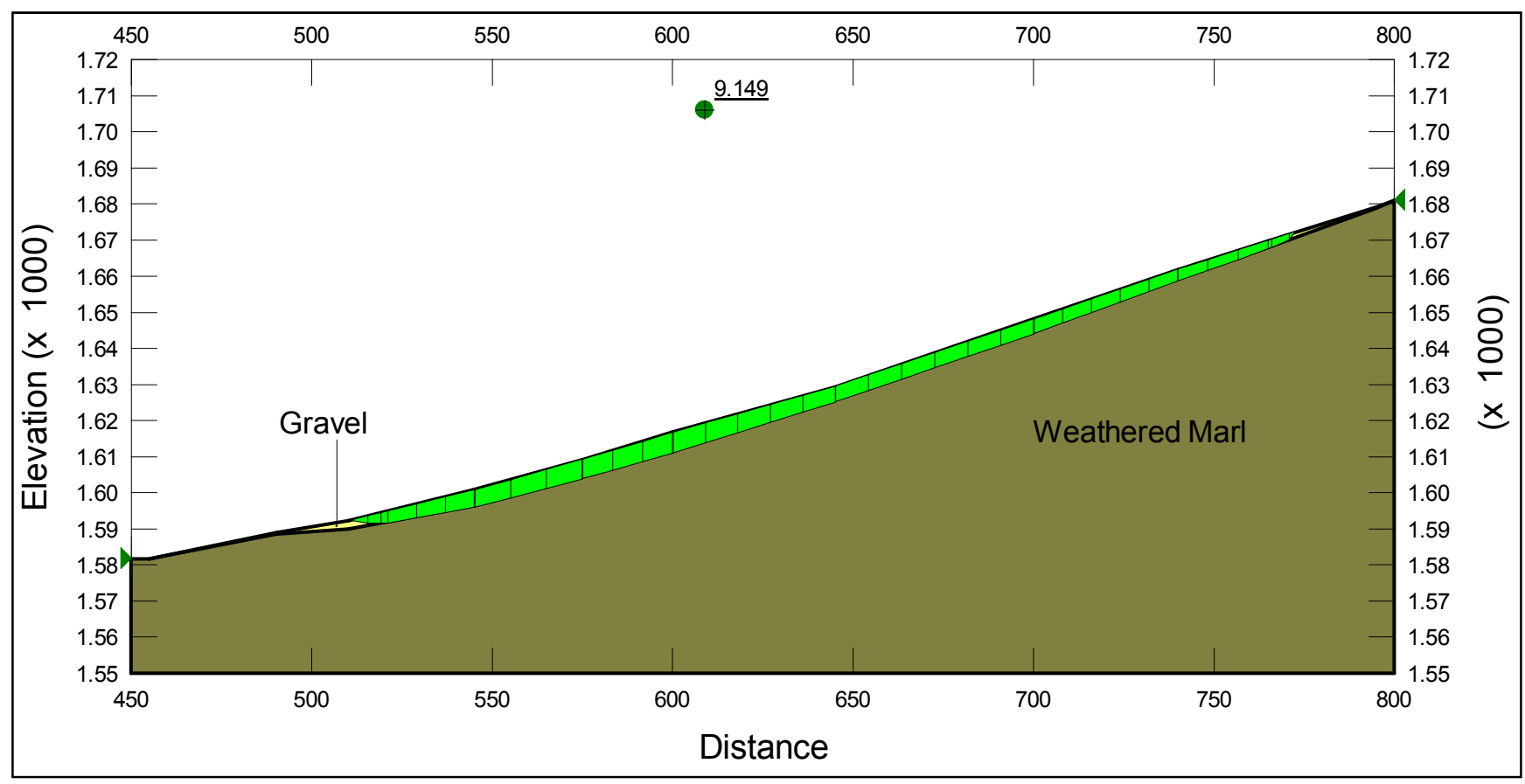

Figure 9. Factor of safety in slope stability analysis, Km. 443 IGAT II.

\section{Conclusions}

In this study, geotechnical properties of three samples, taken from slip surfaces of ancient landslides of the two main active zones are investigated. However, the samples were taken from apparently weak soils, but, unexpectedly, they showed good stability strengthIn the sampling process of the three landslides, samples representative of apparently geotechnically weak rock or poor soil type were the only ones selected for testing and were taken from slip surface/zones with well-defined natural deformation, remolding and slicken siding. Geotechnical and soil shear parameters measured on samples taken from the slip surface showed apparent good results indicating that a landslide should not occur. However this assumption proved to be misleading, for despite these measurements, land sliding did occur. This was especially so in the case of rockslides.

The investigation indicated that the presence of slip surfaces controls the behavior of ancient landslides. Reliance on the geotechnical parameters and the subsequent analyses is misleading. However, geotechnical parameters are of great value for stability analysis when no slip surface or ancient landside exists. The abundance of large-scale ancient landslides in active fold belts is the result of historical earthquakes. Human interference and river undercutting can reactivate ancient landslides but later earthquakes do not. In development projects; the best way is to avoid ancient landslides, but if avoidance is not possible, the main slip surface/zone has to be determined and considered in any design for remedial work. Since no numerical value can be assigned to the slip surface in analyzing an ancient landslide therefore we are left with the enigma that the acceptance of soil test values as essentially the sole reason for determining stability is totally misleading for design purposes.

\section{Acknowledgements}

In this regard; a wide range of people has to be acknowledged, from simple workers, operators of excavators to highly experienced experts of whom are Professor D. F. Branagan for his enthusiasm and his encouragement, A. Fathi for assisting in Analysis, A. Mina for preparation of profiles and data and Khakvaran geotechnical consulting engineers for performing the laboratory tests.

\section{References}

[1] Wang F, Zhang Y, Huo Z, Peng X, Wang S, Yamasaki S (2008) Mechanism for the rapid motion of the Qianjiangping landslide during reactivation by the first impoundment of the Three Gorges Dam reservoir, China. Landslides 5(4):379-386.

[2] Potts DM, Dounias GT, Vaughan PR (1990) Finite element analysis of progressive failure of Carsington embankment. Geotechnique 40(1):79-101.

[3] Potts DM, Kovacevic N, Vaughan PR (1997) Delayed collapse of cut slopes in stiff clay. Geotechnique 47(5):953-982.

[4] Troncone A, Conte E, Donato A (2014) Two and threedimensional numerical analysis of the progressive failure that occurred in an excavation-induced landslide. Eng Geol183:265-275.

[5] Troncone A (2005) Numerical analysis of a landslide in soils with strain-softening behavior. Geotechnique 55(8):585-596.

[6] Hossam, Kishawy, A., Hossam, A. Gabbar, 2010.Review of pipeline integrity management practices. Int. J.Press. Vessels Pip. 87(7), 373-380. 
[7] Huang, F., Lu, Wu, H. Z., 2011.Buried pipeline optimization in landslide area. ICPTT 2011, pp. 2366-2376.

[8] Ma, Y., Chen, Y., Tan, D., Ma T., 2011. Study on application of fiber bragg grating strain tube in deep displacement monitoring of pipeline landslide. ICPTT 2011, pp. 1438-1444.

[9] Deng, D.M., Zhou, X. H., Shen, Y. P., 1988.Calculation of pipeline innerforce and distortion during transverse landslide body (in Chinese). Oil Gas Storage 17(7), 18-22.

[10] Aghanabati, S.A. 2004. "Geology of Iran." Ministry of Industry \& Mine, Geological Survey of Iran, 18.
[11] Pedram, H. 1990. "Earthquakes, Tectonic Activities, and Landslides." Proceedings of the First International Conference on Seismology and Earthquake Engineering, V1, 463 - 470.

[12] Pedram, H. 1995. "A Glance over Iranian Landslides, Occurrence and their Distribution." Proceeding of the First Conference on Methodology of Landslide Hazard Reduction in Iran, International Institute of Earthquake Engineering and Seismology (In Farsi), 365-387.

[13] Nasiri, Sh. Ehteshami, M. 2004. "An Overview to Iranian Landslide." National Geosciences Database of Iran, Geological Survey of Iran. 